\title{
Erbium-Doped AllnGaN Alloys as High-Temperature Thermoelectric Materials
}

\author{
Bed Nidhi Pantha*, I-wen Feng, Krishna Aryal, Jing Li, Jing-Yu Lin, and Hong-Xing Jiang \\ Department of Electrical and Computer Engineering, Texas Tech University, Lubbock, TX 79409, U.S.A.
}

Received March 7, 2011; accepted April 8, 2011; published online April 26, 2011

The potential of Er-doped $\mathrm{Al}_{x} \mathrm{In}_{0.1} \mathrm{Ga}_{0.9-x} \mathrm{~N}$ quaternary alloys as high-temperature thermoelectric (TE) materials has been explored. It was found that the incorporation of $\mathrm{Er}$ significantly decreased the thermal conductivity $(\kappa)$ of $\mathrm{Al}_{x} \ln _{0.1} \mathrm{Ga}_{0.9-x} \mathrm{~N}$ alloys. The temperature-dependent TE properties were measured up to $1055 \mathrm{~K}$ for an $\mathrm{Er}$ and $\mathrm{Si}$ co-doped n-type $\mathrm{Al}_{0.1} \mathrm{In}_{0.1} \mathrm{Ga}_{0.8} \mathrm{~N}$ alloy. The figure of merit $(Z T)$ showed a linear increase with temperature and a value of about 0.3 at $1055 \mathrm{~K}$ was estimated. The ability to survive such high temperature with reasonable TE properties suggests that low-In-content $\mathrm{Er}$ and Si-doped AllnGaN alloys are potential candidate of high-temperature TE materials.

(C) 2011 The Japan Society of Applied Physics

$\mathrm{H}$ igh-temperature thermoelectric (TE) devices offer a great potential for waste heat scavenging from power plants and exhausts of automobiles and aircrafts due to their ability to directly convert heat to electricity. However, their applications are limited to niche markets such as powering satellites in deep space missions where reliability and lifetime are the prime issues rather than conversion efficiency. In order for TE devices to play a key role in energy production and utilization, more efficient TE materials that are suitable for high-temperature applications are needed. The recent progress in low-dimensional materials has opened up tremendous possibilities to manipulate the TE properties to achieve a high TE figure of merit $(Z T)$ and to search new materials. ${ }^{1-6)}$ The figure of merit at a given absolute temperature $T$ is defined as $Z T\left(=S^{2} \sigma T / \kappa\right)$, where $S, \sigma$, and $\kappa$ are the Seebeck coefficient, electrical conductivity, and thermal conductivity, respectively, and gauges the material's TE performance. The TE properties of III-nitrides have recently been examined both experimentally and theoretically by several groups, ${ }^{7-15)}$ with a particular focus on high-temperature TE applications. Due to the outstanding physical properties of III-nitrides, such as the ability for high-power and high-temperature operation, high mechanical strength and stability, and radiation hardness, one can anticipate that III-nitrides could be the next generation TE materials for solid-state power generation.

Many experimental reports reveal that reducing $\kappa$ is the most viable approach of enhancing $Z T$ in state-of-the-art nanostructured materials. ${ }^{1-5,16-22)}$ Abeles ${ }^{16)}$ suggested that semiconductor alloys possess a significantly smaller $\kappa$ compared to their constituent's elements or compounds and hence are considered to be good TE materials. For instance, a reduction in $\kappa$ by two orders of magnitude can be obtained by alloying GaN with $\mathrm{InN}$ for an In-content of around $0.35 .^{7)}$ Nevertheless, such a reduction is not enough to achieve a reasonable value of $Z T$ in many alloys as a reduction in $\kappa$ beyond the alloy limit is very difficult to achieve. Other approaches such as incorporating voids, defects, dislocations, ${ }^{17)}$ grain boundary/interfaces and nanostructures, ${ }^{1-5,18,19)}$ or nanoparticles and dopants ${ }^{2,5,20-22)}$ have been employed to provide additional phonon scattering centers to beat the alloy limit. The overall enhancement in $Z T$ depends upon the ability of a strategy to reduce $\kappa$ while keeping the electrical properties unchanged. Of the various methods, the incorporating of heavy elements and/or nanoparticles has proven to be an effective strategy of

*E-mail address: bed.pantha@ttu.edu reducing $\kappa$ without deteriorating many electrical properties as the wavelength of phonons is much smaller than that of electrons. $^{2,5,22)}$

Here, we discuss the growth and TE properties of Er and Si co-doped AlInGaN [AlInGaN:(Si+Er)] quaternary alloys. The aim of incorporating Er atoms is similar to the approach of incorporating heavy elements or nanoparticles, while codoping with $\mathrm{Si}$ was necessary to achieve n-type conductivity control. AlInGaN:(Si+Er) epilayers were grown on semiinsulating $\mathrm{GaN} / \mathrm{AlN} /$ sapphire templates by low-pressure metal organic chemical vapor deposition. The growth and hence the operational temperature of the AlInGaN material system is predominantly controlled by the amount of Incontent in the alloy; meaning a low In-content can bear higher temperatures. However, thermal stability of AlInGaN at high temperature is better than that of $\mathrm{InGaN}^{23}{ }^{23} \mathrm{We}$ have checked the thermal stability of AlInGaN epilayers deposited on $\mathrm{GaN} / \mathrm{AlN} /$ sapphire templates by measuring the structural and electronic transport properties before and after annealing the epilayers at $1010 \mathrm{~K}$ in air for $3 \mathrm{~h}$. It was found that AlInGaN epilayers with In-contents above 0.3 partially decomposed, while those with In-contents below 0.2 retain their original properties after annealing. Thus, we limit the In-content to $10 \%$ for TE properties study. The growth temperature of $\mathrm{Al}_{x} \mathrm{In}_{0.1} \mathrm{Ga}_{0.9-x} \mathrm{~N}:(\mathrm{Si}+\mathrm{Er})$ was the same as that of $\operatorname{In}_{0.1} \mathrm{Ga}_{0.9} \mathrm{~N}\left(780^{\circ} \mathrm{C}\right)$.

Various characterization techniques such as X-ray diffraction (XRD), $3 \Omega$ method, Hall-effect measurement, and temperature gradient methods were performed to investigate the structural/compositional, thermal, and electrical properties of these quaternary alloys. Details regarding the characterization methods are described elsewhere. ${ }^{7)}$

The $\theta-2 \theta$ XRD curves of (002) reflection obtained from the $\mathrm{Al}_{x} \mathrm{In}_{0.1} \mathrm{Ga}_{0.9-x} \mathrm{~N}$ :Si alloys for different trimethylaluminum (TMAl) flow rates are plotted in Fig. 1(a). The peak angles of XRD curves were shifted toward larger angles as the TMAl flow rate was increased, which implies that the Alcontent in $\mathrm{Al}_{x} \mathrm{In}_{0.1} \mathrm{Ga}_{0.9-x} \mathrm{~N}$ :Si alloys was increasing. Alloy compositions were determined by the peak angles of the XRD curves and using Vegard's law. Electrical properties, free electron concentration $n$ and mobility $\mu$, as functions of Al-content in $\mathrm{Al}_{x} \mathrm{In}_{0.1} \mathrm{Ga}_{0.9-x} \mathrm{~N}: \mathrm{Si}$ alloys are plotted in Fig. 1(b). As expected, $\mu$ was decreased from 115 to $60 \mathrm{~cm}^{2} /(\mathrm{V} \cdot \mathrm{s})$ as Al-content $x$ was increased from 0 to 0.14 due to the larger alloy scattering effect while $n$ remains almost the same. The room temperature $Z T$ values of $\mathrm{Al}_{0.08} \mathrm{In}_{0.1} \mathrm{Ga}_{0.82} \mathrm{~N}: \mathrm{Si}$ and $\mathrm{Al}_{0.14} \mathrm{In}_{0.1} \mathrm{Ga}_{0.76} \mathrm{~N}: \mathrm{Si}$ alloys were measured to be 0.009 and 0.013 , respectively. The low 
Table I. Room-temperature TE properties of AlInGaN alloys.

\begin{tabular}{lcccccc}
\hline \multicolumn{1}{c}{ Sample } & $\begin{array}{c}n \\
\left(\times 10^{19} \mathrm{~cm}^{-3}\right)\end{array}$ & $\begin{array}{c}\mu \\
{\left[\mathrm{cm}^{2} /(\mathrm{V} \cdot \mathrm{s})\right]}\end{array}$ & $\begin{array}{c}\sigma \\
(\Omega \cdot \mathrm{cm})^{-1}\end{array}$ & $\begin{array}{c}S \\
(\mu \mathrm{V} / \mathrm{K})\end{array}$ & $\begin{array}{c}{ }^{2} \\
{[\mathrm{~W} /(\mathrm{m} \cdot \mathrm{K})]}\end{array}$ & $\begin{array}{c}Z T \\
{\left[10^{-4} \mathrm{~W} /\left(\mathrm{m} \cdot \mathrm{K}^{2}\right)\right]}\end{array}$ \\
\hline $\mathrm{In}_{0.10} \mathrm{Ga}_{0.90} \mathrm{~N}: \mathrm{Er}+\mathrm{Si}$ & 0.8 & 86 & 113 & 160 & 1.90 & 2.91 \\
$\mathrm{Al}_{0.14} \mathrm{In}_{0.10} \mathrm{Ga} \mathrm{Ga}_{0.76} \mathrm{~N}: \mathrm{Si}$ & 1.3 & 61 & 128 & 120 & 4.0 & 1.84 \\
$\mathrm{Al}_{0.10} \mathrm{In}_{0.10} \mathrm{Ga}_{0.80} \mathrm{~N}: \mathrm{Er}+\mathrm{Si}$ & 1.3 & 88 & 200 & 123 & 1.67 & 0.013 \\
$\mathrm{Al}_{0.14} \mathrm{In}_{0.10} \mathrm{Ga}_{0.76} \mathrm{~N}: \mathrm{Er}+\mathrm{Si}$ & 1.2 & 45 & 100 & 121 & 1.92 & 0.055 \\
\hline
\end{tabular}

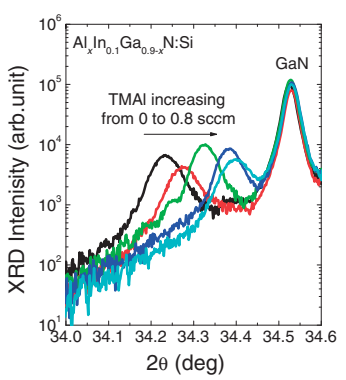

(a)

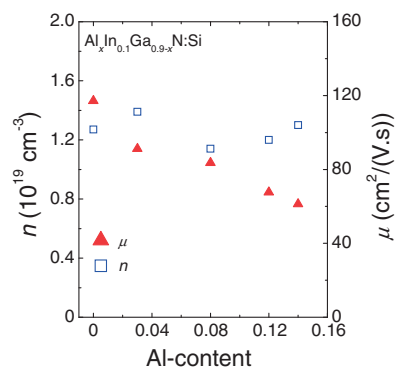

(b)
Fig. 1. (a) (002) XRD $\theta-2 \theta$ spectra of $\mathrm{Al}_{x} \mathrm{In}_{0.1} \mathrm{Ga}_{0.9-x} \mathrm{~N}: \mathrm{Si}$ alloys for varying TMAl flow rate and (b) free electron concentration $n$ and mobility $\mu$ as functions of $\mathrm{Al}$ content $x$ in $\mathrm{Al}_{x} \mathrm{In}_{0.1} \mathrm{Ga}_{0.9-x} \mathrm{~N}: \mathrm{Si}$ alloys.

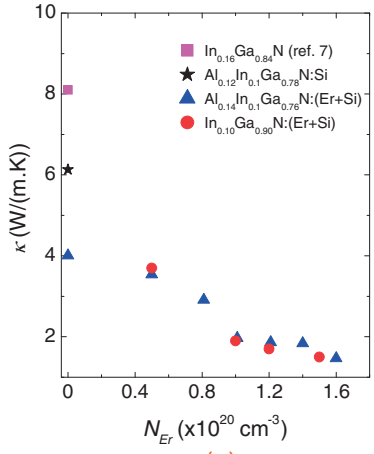

(a)

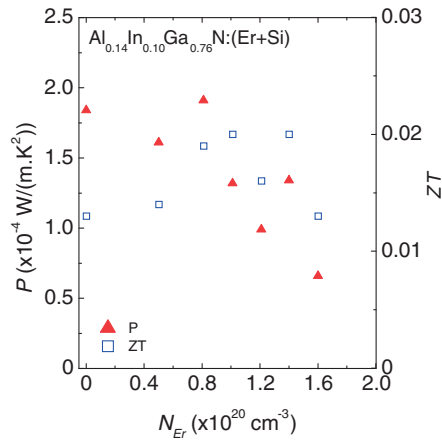

(b)
Fig. 2. (a) Room-temperature thermal conductivity $\kappa$ of AlInGaN alloys measured by differential $3 \Omega$ method as a function of Er doping concentration, $N_{\mathrm{Er}}$ and (b) room-temperature power factor $P$ and $Z T$ as functions of Er doping concentration, $N_{\mathrm{Er}}$ of $\mathrm{Al}_{0.14} \mathrm{In}_{0.1} \mathrm{Ga}_{0.76} \mathrm{~N}:(\mathrm{Er}+\mathrm{Si})$ alloys. Free electron concentration is $\sim 1.2 \times 10^{19} \mathrm{~cm}^{-3}$.

values of $Z T$ are a result of the high values of $\kappa$ in AlInGaN:Si.

The effects of Er doping on the TE properties of the $\mathrm{Al}_{0.14} \mathrm{In}_{0.1} \mathrm{Ga}_{0.76} \mathrm{~N}$ alloy have been investigated with varying Er doping concentrations $N_{\mathrm{Er}}$. Figure 2(a) shows the $N_{\text {Er}}$-dependent room-temperature $\kappa$ of $\mathrm{Al}_{0.14} \mathrm{In}_{0.1} \mathrm{Ga}_{0.76} \mathrm{~N}$ : $(\mathrm{Er}+\mathrm{Si})$ alloys along with $\operatorname{In}_{0.1} \mathrm{Ga}_{0.9} \mathrm{~N}:(\mathrm{Er}+\mathrm{Si})$ alloys, an undoped $\mathrm{In}_{0.16} \mathrm{Ga}_{0.84} \mathrm{~N}$ alloy, and a Si-doped $\mathrm{Al}_{0.12} \mathrm{In}_{0.1^{-}}$ $\mathrm{Ga}_{0.78} \mathrm{~N}$ alloy. It is evident that the incorporation of $\mathrm{Er}$ significantly decreased $\kappa$ of $\mathrm{Al}_{x} \mathrm{In}_{0.1} \mathrm{Ga}_{0.9-x} \mathrm{~N}$ [from around 6 to $1.4 \mathrm{~W} /(\mathrm{m} \cdot \mathrm{K})$ ]. Room temperature $\kappa$ of $\mathrm{Al}_{0.14} \mathrm{In}_{0.1} \mathrm{Ga}_{0.76} \mathrm{~N}$ : $(\mathrm{Er}+\mathrm{Si})$ was decreased from 4.1 to $1.4 \mathrm{~W} /(\mathrm{m} \cdot \mathrm{K})$ when $N_{\mathrm{Er}}$ was increased from 0 to $1.6 \times 10^{20} \mathrm{~cm}^{-3}$. A similar trend was also observed in $\operatorname{In}_{0.1} \mathrm{Ga}_{0.9} \mathrm{~N}:(\mathrm{Er}+\mathrm{Si})$ alloys. This reduction in $\kappa$ is attributed to the fact that the incorporation of $\mathrm{Er}$ atoms effectively scattered and/or slowed down phonons by providing additional scattering centers with large mass. While the differences in measured $\kappa$ between the $\mathrm{Al}_{0.14} \mathrm{In}_{0.1} \mathrm{Ga}_{0.76} \mathrm{~N}:(\mathrm{Er}+\mathrm{Si})$ and $\mathrm{In}_{0.1} \mathrm{Ga}_{0.9} \mathrm{~N}:(\mathrm{Er}+\mathrm{Si})$ are within the experimental error (differential $3 \Omega$ method could introduce as high as $20 \%$ error in measured $\kappa$ ) at higher $N_{\text {Er }}$, we did see the reduced $\kappa$ in $\operatorname{In}_{0.1} \mathrm{Ga}_{0.9} \mathrm{~N}$ due to the incorporation of $\mathrm{Al}$ at low or zero Er concentration. These results suggest that $\mathrm{Er}$ is much more effective than $\mathrm{Al}$ to reduce $\kappa$ of InAlGaN alloys. The exact reasons for the weaker effect of $\mathrm{Al}$ on $\kappa$ reduction as compared to that of Er are not fully understood, however larger atomic mass and radius of the Er atom should be the primary reason of dominant effect of $\mathrm{Er}$ ( $\mathrm{Er}$ atom is $6 \times$ heavier and $1.4 \times$ larger than $\mathrm{Al}$ atom). In addition to provide the strong scattering centers for phonons, sufficiently large $N_{\mathrm{Er}}$ could significantly slow down the phonon's velocity as it is inversely proportional to the square root of the atomic mass, which results in lower $\kappa$. Reduction in $\kappa$ due to the heavy element substitution has also been observed in other material systems. ${ }^{5,22)}$

The room-temperature thermoelectric power factor $P$ and $Z T$ as functions of $N_{\mathrm{Er}}$ of $\mathrm{Al}_{0.14} \mathrm{In}_{0.1} \mathrm{Ga}_{0.76} \mathrm{~N}$ : $(\mathrm{Er}+\mathrm{Si})$ alloys are plotted in Fig. 2(b). $Z T$ has a peak value of 0.02 at around $N_{\mathrm{Er}}=10^{20} \mathrm{~cm}^{-3}$, while $P$ decreases with $N_{\mathrm{Er}}$. A trade-off between $\mu$ and $N_{\mathrm{Er}}$ is the reason to have a peak value of $Z T$ although $\kappa$ continuously decreases with increasing $N_{\mathrm{Er}}$. However, we were able to increase roomtemperature $Z T$ to 0.055 , by reducing the Al-content in $\mathrm{Al}_{x} \mathrm{In}_{0.1} \mathrm{Ga}_{0.9-x} N:(\mathrm{Er}+\mathrm{Si})$ alloys to 0.1 . The enhancement in $Z T$ in $\mathrm{Al}_{0.1} \mathrm{In}_{0.1} \mathrm{Ga}_{0.8} \mathrm{~N}$ :(Er+Si) over $\mathrm{Al}_{0.14} \mathrm{In}_{0.1} \mathrm{Ga}_{0.76} \mathrm{~N}$ : $(\mathrm{Er}+\mathrm{Si})$ is mainly due to the enhanced $\mu$ since it increases with a decrease of Al-content [Fig. 1(b)]. The TE properties of some optimized alloys are compared in Table I. Although room-temperature $Z T$ values of $\mathrm{In}_{0.1} \mathrm{Ga}_{0.9} \mathrm{~N}:(\mathrm{Er}+\mathrm{Si})$ and $\mathrm{Al}_{0.1} \mathrm{In}_{0.1} \mathrm{Ga}_{0.8} \mathrm{~N}:(\mathrm{Er}+\mathrm{Si})$ are similar, we preferred $\mathrm{Al}_{0.1} \mathrm{In}_{0.1^{-}}$ $\mathrm{Ga}_{0.8} \mathrm{~N}:(\mathrm{Er}+\mathrm{Si})$ alloys because, for the same In content, AlInGaN alloys have been found more thermally stable than InGaN alloys at high temperature. ${ }^{23)}$

The Seebeck coefficient $S$ and electrical conductivity $\sigma$ of an optimized quaternary alloy, $\mathrm{Al}_{0.1} \mathrm{In}_{0.1} \mathrm{Ga}_{0.8} \mathrm{~N}$ :(Er+Si), were measured simultaneously from room temperature to about $1055 \mathrm{~K}$. As shown in Fig. 3, as temperature was increased from room temperature to $1055 \mathrm{~K}, S$ value was increased from 124 to $193 \mu \mathrm{V} / \mathrm{K}$ but $\sigma$ decreased from 200 to $135(\Omega \cdot \mathrm{cm})^{-1}$. The overall TE performance is enhanced at higher temperatures since the power factor increases with an increase of temperature. The ability of the material to survive such a high temperature without any degradation of properties attests that low In-content AlInGaN:(Er+Si) alloys are potential candidates for high-temperature TE applications. 


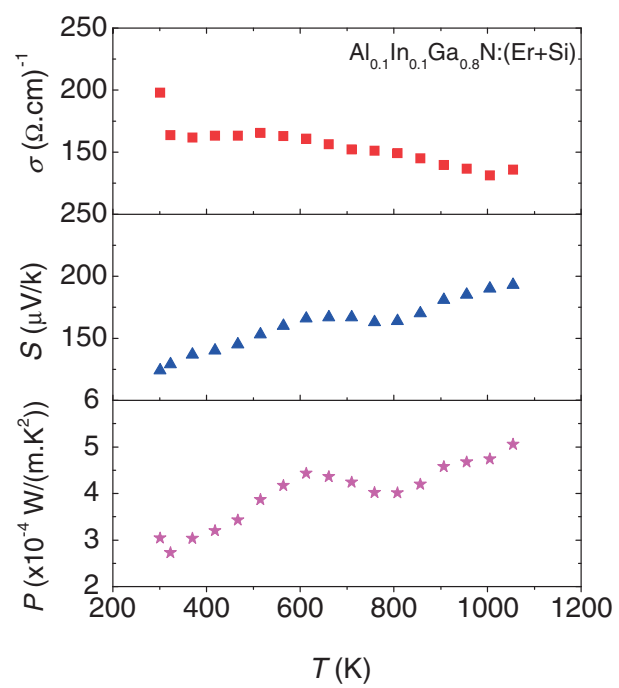

Fig. 3. Temperature-dependent electrical conductivity $\sigma$, Seebeck coefficient $S$, and power factor $P$ of $\mathrm{Al}_{0.1} \mathrm{In}_{0.1} \mathrm{Ga}_{0.8} \mathrm{~N}:(\mathrm{Er}+\mathrm{Si})$ alloy measured by a thermal analysis system (ULVAC ZEM-3, type M10).

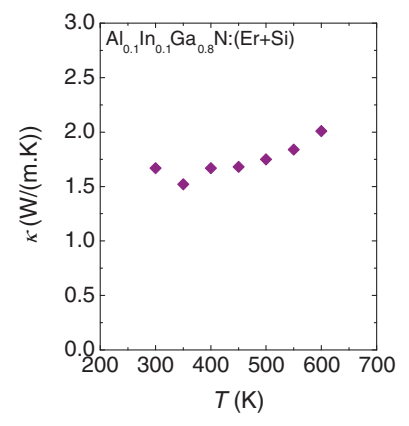

(a)

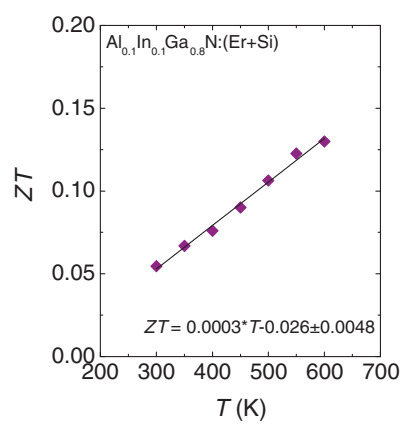

(b)
Fig. 4. (a) Temperature-dependent thermal conductivity $\kappa$ of $\mathrm{Al}_{0.1} \mathrm{In}_{0.1} \mathrm{Ga}_{0.8} \mathrm{~N}$ :(Er+Si) alloy measured by differential $3 \Omega$ method. (b) Temperature-dependent $Z T$ of $\mathrm{Al}_{0.1} \mathrm{In}_{0.1} \mathrm{Ga}_{0.8} \mathrm{~N}:(\mathrm{Er}+\mathrm{Si})$ alloy. The solid line is the linear fit of the experimental data.

The temperature-dependent $\kappa$ of an $\mathrm{Al}_{0.1} \mathrm{In}_{0.1} \mathrm{Ga}_{0.8} \mathrm{~N}$ : $(\mathrm{Er}+\mathrm{Si})$ alloy measured by the differential $3 \Omega$ method is shown in Fig. 4(a). The measured $\kappa$ is found to increase with an increase of temperature. Such a temperature-dependent behavior of $\kappa$ generally occurs in disordered systems and has also been seen in hydride vapor-phase epitaxy (HVPE)grown AlGaN alloys. ${ }^{24)}$ Combining these properties, the temperature-dependent $Z T$ is deduced and plotted in Fig. 4(b). A linear increase with temperature in $Z T$ is observed and a $Z T$ value of $\sim 0.3$ was extrapolated at $1055 \mathrm{~K}$. This value is much larger than that of other nitrides, $\mathrm{Al}_{0.28} \operatorname{In}_{0.72} \mathrm{~N} \quad\left(Z T=0.1\right.$ at $873 \mathrm{~K}$, experimental $\left.{ }^{11)}\right)$ and $\mathrm{Al}_{0.4} \mathrm{Ga}_{0.6} \mathrm{~N}\left(Z T=0.2\right.$ at $1000 \mathrm{~K}$, calculation $\left.{ }^{12)}\right)$. However, $Z T$ of $\mathrm{Al}_{0.1} \mathrm{In}_{0.1} \mathrm{Ga}_{0.8} \mathrm{~N}:(\mathrm{Er}+\mathrm{Si})$ is still about three times smaller than that of $\mathrm{n}-\mathrm{Si}_{0.8} \mathrm{Ge}_{0.2}$ alloy $(Z T=0.9$ at $1175 \mathrm{~K}$, experimental ${ }^{24)}$, which is the only material used in radioisotope thermoelectric generators (RTGs) for the past 50 years. Compared with the $n-\mathrm{Si}_{0.8} \mathrm{Ge}_{0.2}$ alloy, smaller $Z T$ of $\mathrm{Al}_{0.1} \mathrm{In}_{0.1} \mathrm{Ga}_{0.8} \mathrm{~N}:(\mathrm{Er}+\mathrm{Si})$ is mainly due to the much smaller value of $S$ for a given $n(120$ vs $360 \mu \mathrm{V} / \mathrm{K}$ at $n=1 \times$ $\left.10^{19} \mathrm{~cm}^{-3}\right){ }^{25}$ ) Further improvements in material quality and incorporation of nanostructures in AlInGaN alloys are needed to fully realize the potential of III-nitrides for high-temperature TE applications.

We have investigated the TE properties of n-type $\mathrm{Al}_{x} \mathrm{In}_{0.1} \mathrm{Ga}_{0.9-x} \mathrm{~N}:(\mathrm{Er}+\mathrm{Si})$ quaternary alloys and demonstrated the suitability of low In-content AlInGaN:(Er+Si) alloys for high temperature TE applications as they can survive up to $1055 \mathrm{~K}$. Because of the large atomic mass of Er element compared to that of $\mathrm{Al}$ element, substitution of $\mathrm{Er}$ in $\mathrm{In}_{0.1} \mathrm{Ga}_{0.9} \mathrm{~N}$ alloys is found to be much more effective in terms of reducing the thermal conductivity when the concentration of Er is sufficiently large. The figure of merit $Z T$ is estimated to be $\sim 0.3$ at $1055 \mathrm{~K}$ for $\mathrm{Al}_{0.1} \mathrm{In}_{0.1} \mathrm{Ga}_{0.8} \mathrm{~N}$ : $(\mathrm{Er}+\mathrm{Si})$.

Acknowledgments This research was supported by DOE (ER46552). Jiang and Lin are grateful to the AT\&T Foundation for the support of Edward Whitacre and Linda Whitacre Endowed Chairs. We would like to acknowledge Evan Sohm of ULVAC Technologies, Inc. for the measurement of high temperature Seebeck coefficient and electrical conductivity (Fig. 3).

1) R. Venkatasubramanian, E. Slivola, T. Colpitts, and B. O'Quinn: Nature 413 (2001) 597.

2) T. C. Harman, P. J. Taylor, M. P. Walsh, and B. E. Laforge: Science 297 (2002) 2229.

3) A. I. Hochbaum, R. Chen, R. D. Delgado, W. Liang, E. C. Garnett, M. Najarian, A. Majumdar, and P. Yang: Nature 451 (2008) 163.

4) L. D. Hick and M. S. Dresselhaus: Phys. Rev. B 47 (1993) 16631.

5) W. Kim, J. Zide, A. Gossard, D. Klenov, S. Stemmer, A. Shakouri, and A. Majumdar: Phys. Rev. Lett. 96 (2006) 045901.

6) H. Ohta, S. Kim, Y. Mune, T. Mizoguchi, K. Nomura, S. Ohata, T. Nomura, Y. Nakanishi, Y. Ikuhara, M. Hirano, H. Hosono, and K. Koumoto: Nat. Mater. 6 (2007) 129.

7) B. N. Pantha, R. Dahal, J. Li, J. Y. Lin, H. X. Jiang, and G. Pomrenke: Appl. Phys. Lett. 92 (2008) 042112.

8) B. N. Pantha, R. Dahal, J. Li, J. Y. Lin, H. X. Jiang, and G. Pomrenke: J. Electron. Mater. 38 (2009) 1132.

9) B. C. Daly, H. J. Maris, A. V. Nurmikko, M. Kuball, and J. Han: J. Appl. Phys. 92 (2002) 3820.

10) S. Yamaguchi, R. Izaki, K. Yamagiwa, K. Taki, Y. Iwamura, and A. Yamamoto: Appl. Phys. Lett. 83 (2003) 5398.

11) S. Yamaguchi, Y. Iwamura, and A. Yamamoto: Appl. Phys. Lett. 82 (2003) 2065.

12) W. Liu and A. A. Balandin: J. Appl. Phys. 97 (2005) 123705.

13) H. Tong, J. Zhang, G. Liu, J. A. Herbsommer, G. S. Huang, and N. Tansu: Appl. Phys. Lett. 97 (2010) 112105.

14) H. Tong, H. Zhao, V. A. Handara, J. A. Herbsommer, and N. Tansu: Proc. SPIE 7211 (2009) 721103.

15) A. Sztein, H. Ohta, J. Sonoda, A. Ramu, J. E. Bowers, S. P. DenBaars, and S. Nakamura: Appl. Phys. Express 2 (2009) 111003.

16) B. Abeles: Phys. Rev. 131 (1963) 1906.

17) C. B. Vining: J. Appl. Phys. 69 (1991) 331.

18) B. Poudel, Q. Hao, Y. Ma, Y. Lan, A. Minnich, B. Yu, X. Yan, D. Wang, A. Muto, D. Vashaee, X. Chen, J. Liu, M. Dressehaus, G. Chen, and Z. Ren: Science 320 (2008) 634.

19) T. Borca-Tasciuc, J. Liu, T. Zeng, W. Liu, D. W. Song, C. D. Moore, G. Chen, K. L. Wang, and M. S. Goorsky: Superlattices Microstruct. 28 (2000) 199.

20) M. Asheghi, K. Kurabayashi, R. Kasnavi, and K. E. Goodson: J. Appl. Phys. 91 (2002) 5079.

21) O. Yamashita and N. Sadatomi: J. Appl. Phys. 88 (2000) 245

22) M. Mikami, S. Tanaka, and K. Kobayashi: J. Alloys Compd. 484 (2009) 444.

23) S. N. Lee, H. S. Paek, H. Kim, K. K. Kim, Y. H. Cho, T. Jang, and Y. Park: J. Cryst. Growth 310 (2008) 3881.

24) W. Liu and A. A. Balandin: J. Appl. Phys. 97 (2005) 073710.

25) J. P. Dismukes, L. Ekstrom, E. F. Steigmeier, I. Kudman, and D. S. Beers: J. Appl. Phys. 35 (1964) 2899. 